\title{
Interdisciplinaridade, Materialismo Histórico-Dialético e Paradigma da Complexidade: Articulações em Torno da Pesquisa em Educação Ambiental Crítica
}

\author{
Interdisciplinarity, Historical and Dialectical Materialism and Paradigm of Complexity: \\ Articulations Around Research in Critical Environmental Education
Interdisciplinaridad, Materialismo Histórico-Dialéctico y el Paradigma de Complejidad: Articulaciones Alrededor de la Investigación en la Educación Ambiental Crítica

César Augusto Costa ${ }^{1}$

Carlos Frederico Loureiro ${ }^{2}$

\begin{abstract}
Resumo
O objetivo do nosso ensaio é abordar as implicações epistêmicas e políticas da interdisciplinaridade, a partir do materialismo histórico-dialético e de suas relações com o paradigma complexo, na pesquisa em educação ambiental (EA) crítica. Inicialmente buscaremos problematizar a interdisciplinaridade na EA em suas múltiplas dimensões para a compreensão da questão ambiental. Em seguida, analisaremos o problema do conhecimento com base em duas compreensões da pesquisa em educação ambiental, a visão sistêmica e a do materialismo históricodialético. Ao final da argumentação, pontuaremos as implicações epistemológicas e políticas da relação entre interdisciplinaridade, materialismo histórico-dialético e paradigma complexo, visando ao enfrentamento das relações destrutivas da natureza e do ser humano historicamente estabelecidas no capitalismo. Reiteramos que a interdisciplinaridade, entendida como pressuposto da pesquisa em EA em uma perspectiva crítica, não pode ser adotada em seu sentido lógico-formal ou ideal, fora de metodologias que busquem apreender o movimento histórico e as múltiplas determinações que constituem a realidade. Compreendemos que a teoria da complexidade, a interdisciplinaridade e a dialética marxista se aproximam e contribuem nos projetos de transformação societária, quer redefinindo paradigmas ou modos de pensar e atuar, individual ou coletivamente.
\end{abstract}

Palavras-chave: Interdisciplinaridade. Materialismo histórico-dialético. Paradigma complexo. Pesquisa em educação ambiental crítica.

\begin{abstract}
This article aims to address the epistemic and political implications of interdisciplinarity from historical-dialectical materialism and its relations with the complex paradigm in critical environmental education (EE) research. Initially, interdisciplinarity in EE in its multiple dimensions to understand the environmental issue is problematize. Next, the knowledge issue is analyzed based on two understandings of research in environmental education, the systemic and the historical-dialectical materialism views. At the end of the argument, we will point out the epistemological and political implications of the relationship between interdisciplinarity, historical-dialectical materialism and paradigm of complexity, aiming to confront the destructive relations of nature and human beings historically established in capitalism. We reiterate that interdisciplinarity, understood as a precondition for EE research in a critical perspective, cannot be adopted in its logical-formal or ideal sense or disregarding methodologies that seek to apprehend the historical movement and how it is more than a determination. We understand that the theory of complexity, the interdisciplinarity and the Marxist dialectical approach contribute to the projects of societal transformation, either by redefining paradigms, ways of thinking and acting, individually or collectively.
\end{abstract}

Keywords: Interdisciplinarity. Historical-dialectical materialism. Paradigm of complexity. Research in Critical Environmental Education.

\footnotetext{
${ }^{1}$ Sociólogo. Doutor em Educação Ambiental/FURG. Professor no Programa de Pós-Graduação em Política Social e Direitos Humanos/UCPEL. Coordenador do Núcleo de Estudos Latino-Americano (NEL/UCPEL). Pesquisador do Laboratório de Investigaçção em Educação, Ambiente e Sociedade (LIEAS/UFRJ). E-mail: csc193@hotmail.com

${ }^{2}$ Biólogo. Doutor em Serviço Social/UFRJ. Professor Titular no Programa de Pós-Graduação em Educação/UFRJ. Coordenador do Laboratório de Investigaçção em Educação, Ambiente e Sociedade (LIEAS/UFRJ). Bolsista do Cnpq/Brasil. E-mail: frederico89@gmail.com
} 


\section{Resumen}

El objetivo de nuestro ensayo es abordar las implicaciones epistémicas y políticas de la interdisciplinariedad, basadas en el materialismo histórico-dialéctico y sus relaciones con el paradigma de complejidad, en la investigación de la educación ambiental crítica (EA). Inicialmente buscaremos problematizar la interdisciplinariedad en EA en sus múltiples dimensiones para comprender el problema ambiental. A continuación, analizaremos el problema del conocimiento a partir de dos interpretaciones de la investigación en educación ambiental, la visión sistémica y la del materialismo histórico-dialéctico. Al final del argumento, señalaremos las implicaciones epistemológicas y políticas de la relación entre interdisciplinariedad, materialismo históricodialéctico y paradigma de complejidad, con el objetivo de confrontar las relaciones destructivas de la naturaleza y del ser humano históricamente establecidas en el capitalismo. Reiteramos que la interdisciplinariedad, entendida como una presuposición de investigación en EA desde una perspectiva crítica, no puede adoptarse en su sentido lógico-formal o ideal, fuera de las metodologías que buscan captar el movimiento histórico y las múltiples determinaciones que constituyen la realidad. Entendemos que la teoría de la complejidad, la interdisciplinariedad y la dialéctica marxista se unen y contribuyen a proyectos de transformación social, ya sea redefiniendo paradigmas o formas de pensar y actuar, individual o colectivamente.

Palabras-clave: Interdisciplinariedad. Materialismo histórico-dialéctico. Paradigma complejo. Investigación en educación ambiental crítica.

\section{Premissas introdutórias: interdisciplinaridade, materialismo histórico-dialético e complexidade}

A interdisciplinaridade, com seus problemas, avanços e desafios, tem contribuído para problematizações importantes na área da pesquisa e da práxis pedagógica ambiental. Isso se dá porque o "ambiente", entendido em suas múltiplas determinações (sociais, políticas, econômicas e culturais) e mediações com o mundo natural, é por definição um campo social interdisciplinar. Concebemos a interdisciplinaridade como um processo dialético que leva em conta as contradições constituintes dos complexos fenômenos sociais e naturais, sendo possível afirmar que não se pode almejá-la enquanto se desconsiderar a categoria da totalidade social, cujos aspectos são interdependentes e ganham significado no contexto do qual fazem parte.

A interdisciplinaridade surgiu no continente europeu, na França e na Itália, em meados da década de 1960, quando os movimentos estudantis tinham como principal reivindicação um novo estatuto de universidade. Tal questão apontava a alienação da academia quanto aos problemas cotidianos e o modo como esta limitava o olhar de seus alunos numa única e restrita visão de mundo. Ao final dessa década, os estudantes universitários dimensionaram esse problema a partir de suas posições anticapitalistas que, nessa esteira, chegaram à América Latina - primeiro no México, em 1968, e depois na Argentina, em 1969, com o Cordobazo. Essas posições encontravam apoio numa crítica interna do funcionamento da instituição universitária e do lugar do saber no capitalismo (FOLLARI, 2004). O movimento latinoamericano discutia a cisão entre teoria e prática e a ausência de questões de relevância social nos conteúdos curriculares. Nesse momento, decidiu-se dar lugar às reinvindicações dos estudantes, sendo a interdisciplinaridade um alicerce para tais questionamentos. Sem demora, optou-se por incorporar essas demandas ao discurso oficial, absorvendo seu potencial crítico.

Foi assim que se chegou à hipótese de que a interdisciplinaridade podia dar lugar a uma superação da excessiva especialização, chegando-se também à conclusão de que ela podia fornecer meios para vincular o conhecimento à prática, permitindo, portanto, situar seu lugar dentro da estrutura social em seu conjunto. (FOLLARI, 2004, p. 130)

A reflexão crítica acerca da interdisciplinaridade na produção em educação ambiental (EA) no Brasil adquire importância no cenário de questionamento do projeto societário atual, que a torna ainda mais necessária como contraponto aos impactos destrutivos causados pelo desenvolvimento econômico ao longo do processo civilizatório, que tem na exclusão uma de 
suas facetas. Todas as reflexões indicam, nesse cenário de discussão do ambientalismo como movimento social, a crise civilizatória e dos referenciais epistemológicos, filosóficos e políticos que vêm sustentando a modernidade (QUINTAS, 2009). Sem dúvida, repensar a pesquisa em EA, nesse contexto, implica repensar o processo educativo. "Isso porque não se trata, de modo algum, de um segmento isolado de nossa prática social; ao contrário, sua relação com o social, com o político, com o econômico é íntima e profunda. Hoje, finalmente, nos demos conta de que nossa vida social pulsa articula da com nossa vida natural" (SEVERINO, 2001, p. 10).

Para compreendermos esses fatores, bem como as implicações da crise civilizatória, é preciso apreender o fenômeno dessa crise na sua totalidade e no seu movimento, desvelando os interesses sociais, políticos e econômicos a ele vinculados. Ou seja, reconhecer a realidade como processo multidimensional e complexo, que possui aspectos gerais e específicos, permanentes e transitórios, visíveis e invisíveis, materiais e não materiais, agindo sobre os outros em forma de tensões, conflitos e contradições, e constituindo-se à parte de uma realidade mais ampla (QUINTAS, 2009). Nesse sentido, a questão ambiental resulta das relações que os homens estabelecem entre si e com a natureza. Porto Gonçalves $(1988$, p. 14) nos indica de forma clara essa mediação:

\begin{abstract}
a questão ambiental não pode ser reduzida ao campo específico das ciências da natureza ou das ciências humanas. Ela convoca diversos campos do saber a depor. A questão ambiental na verdade diz respeito ao modo como a sociedade se relaciona com a natureza. Nela estão implicadas as relações sociais e as complexas relações entre o mundo físico-químico e orgânico. Nenhuma área do conhecimento específico tem competência para decidir sobre ela, embora muitas tenham o que dizer.
\end{abstract}

Assim, a pesquisa em EA que busca considerar a centralidade epistemológica da categoria interdisciplinaridade, particularmente a que se insere na perspectiva crítica - foco deste ensaio -, parte do pressuposto de que o "todo e parte" dialeticamente formam uma unidade diversa, que se estabelece em um movimento dinâmico, contraditório e complementar, mutuamente constituído (LOUREIRO, 2004). Do contrário, esse campo de estudos recairia em um holismo generalista, no globalismo desconexo da localidade (estruturalismo, quando o todo domina as partes), ou na fragmentação e no isolamento das partes (funcionalismo, quando a parte domina ou ignora o todo) para entendermos nossa relação com o ambiente. Assumir tal pressuposto significa superar as formas de apropriação que propiciam a dicotomia entre sociedade e natureza, levando em consideração todas as relações que nos situam no planeta e que acontecem na e pela sociedade.

Para refletir sobre esses elementos, consideramos ser necessário também elencar as contribuições do que é denominado por inúmeros intelectuais e cientistas de paradigma da complexidade (MORIN, 2000), considerado um novo método para o saber. A complexidade ambiental se define no sentido de que a vida é constituída por dimensões conexas, definidas mutuamente pelas relações estabelecidas, envolvendo ordem e desordem, erro e acerto, risco e incerteza numa reorganização permanente (MORIN, 1999). A complexidade, portanto, implica uma transformação contínua para superar paradigmas simplificadores que operam a disjunção homem-natureza ou reduzem o ser humano à natureza de modo indistinto.

O paradigma complexo, com vasta contribuição para a pesquisa em EA, faz parte da tradição dialética que visa uma síntese entre idealismo e materialismo. Para ser um instrumento transformador, é necessário que esse paradigma se constitua em algo mais do que um método para uma nova teoria, não podendo, assim, prescindir de uma síntese teórico-prática entre educadores e outros trabalhadores no exercício de sua cidadania, sob pena de se criar um novo dualismo e, assim, regredir em relação ao marxismo, em vez de dialeticamente superá-lo (LOUREIRO, 2004, p. 70).

Igualmente, para a perspectiva crítica assumida neste ensaio, a pesquisa em EA exige que se considere uma dimensão ontológica na produção do conhecimento. Para essa dimensão, 
a realização da natureza humana é aquilo que nos distingue como seres naturais das demais espécies, pois somos produtores da nossa história e de meios de vida, em ações que pressupõem a capacidade de definir finalidades com base em relações sociais concretas (LOUREIRO, 2006a). Dessa maneira, nos atrevemos a conceber que a complexidade e o método dialético marxista dialogam na construção de um projeto de transformação da sociedade, quer definindo paradigmas (LOUREIRO, 2006a) ou modos de pensar e atuar.

No entanto, há algumas questões que norteiam nosso ensaio: como seria pensar de modo complexo a interdisciplinaridade? Quais implicações poderíamos estabelecer a partir do paradigma complexo para a EA crítica, alicerçados no materialismo-histórico e vice-versa? Que vínculos podemos estabelecer entre as duas perspectivas para a discussão ambiental? Que relações existem entre o enfoque sistêmico e sua crítica a partir do materialismo-histórico na pesquisa em EA crítica?

Alicerçado nos pontos indicados, este artigo enfrentará essas questões sistematizandoas em três tópicos. Neste primeiro tópico introdutório, reiteramos a relevância da interdisciplinaridade, do materialismo histórico-dialético e da complexidade para a discussão na pesquisa em EA de orientação crítica. No segundo tópico, problematizamos a interdisciplinaridade a partir do conhecimento de duas vertentes epistemológicas atuais para o debate da pesquisa em EA: a perspectiva sistêmica e a materialista histórica. No terceiro, analisamos a compreensão do materialismo histórico-dialético sobre essa discussão, encontrando na teoria da complexidade e na tradição marxista (LOUREIRO, 2006a, LOUREIRO; VIÉGAS, 2007, 2012; VIÉGAS, 2010) um esforço de articulação que, em última instância, traz contribuições para o debate e para a materialidade da interdisciplinaridade no campo. Nas considerações finais, refletimos a respeito das implicações epistemológicas e políticas da relação entre interdisciplinaridade, materialismo histórico-dialético e EA à luz do paradigma complexo, visando enfrentar e questionar as relações historicamente estabelecidas pelo marco capitalista.

\section{$2 \mathrm{O}$ caráter do conhecimento e as tendências na pesquisa em EA}

Primeiramente, para relacionarmos interdisciplinaridade e práxis pedagógica emancipatória, estamos nos referindo de forma mais direta a processos complexos e à historicidade do real, o que nos remete a um cenário marcado por diferenças epistêmicas (BIANCHETTI; JANTSCH, 2003).

Esses elementos iniciais indicam que atualmente são postas em debate duas perspectivas distintas, fundadas sobre modelos específicos de se entender o processo educativo, bem como de compreensão da sociedade, partindo da apropriação de duas tendências que, independentemente de terem a questão ambiental como objeto de estudo, estruturam-se sobre categorias centrais para a perspectiva interdisciplinar na pesquisa em EA: uma tendência sistêmica e a perspectiva materialista histórica. A primeira busca, em seu bojo filosófico, reiterar que a parte somente pode ser compreendida a partir do todo na explicação da realidade, o que inclui formulações dialéticas desde Heráclito e os orientais, e a reunião de teorias sistêmicas originadas das ciências naturais (LOUREIRO, 2006e). Já a segunda tendência, materialista histórica, alia esforços no sentido de compreender a interdisciplinaridade tecida a partir dos processos de produção da existência e de produção do conhecimento através da práxis (BIANCHETTI; JANTSCH, 2003). Daí, a relevância de trazermos essas duas concepções sobre o caráter do conhecimento e suas implicações teórico-metotodológicas para a interdisciplinaridade na pesquisa em EA.

Contrariando a tendência hegemônica que aponta a "unidade do conhecimento" (na visão sistêmica), postulamos a necessidade de conceber neste debate a interdisciplinaridade na EA como um elemento teórico-metodológico marcado pela diferença, totalidade, mediação, 
contradição e práxis como princípios tensionantes das relações sociais de produção capitalista, enquanto base ontológica para a compreensão da pesquisa em EA crítica. Passamos, primeiramente, à tendência sistêmica.

\subsection{A concepção da "unidade" perdida (visão sistêmica)}

A visão sistêmica é uma perspectiva em voga e que conta com muitos adeptos na pesquisa no Brasil, principalmente entre educadores ambientais. $\mathrm{NaEA}$, muito se discute acerca da sua relevância para o debate ambiental. Nessa tendência interagem diversos pontos de vista, posto que um sistema pode ser definido como um conjunto de partes coordenadas entre si, no qual as leis ordenam os fenômenos, que são vistos como fluxos, processos ou conjunto de unidades em inter-relações mútuas (BERTALANFFY, 1977). Tomamos como ponto de partida e de chegada que a EA é uma práxis social, cujo fim é o aprimoramento do sujeito, que pode ser redefinido a partir dos diversos saberes existentes numa cultura diante das exigências da vida social. Levando em conta tais argumentos, desdobram-se alguns problemas na efetivação das abordagens sistêmicas.

Assim, questionamos: que implicações poderíamos estabelecer a partir dessa tendência para a EA crítica, alicerçados no materialismo-histórico? Para a tendência sistêmica, é necessária a leitura direta dos fenômenos sociais com base em modelos matriciais de retroação alimentados por feedbacks. Tal visão gera um grau de incerteza de ação intencional para além da previsibilidade de qualquer modelo, pois uma questão é alimentar, outra retroalimentar, e outra bem diferente é intervir conscientemente na ação social. Assim, a visão sistêmica contribui para a emergência de perspectivas teóricas que procuram relacionar sistemas sociais e sistemas naturais em construções interdisciplinares embasadas no conceito de autopoiese (FLORIANI; KNECHTEL, 2003). Nessa perspectiva, recai-se na ilusória certeza de se ter alcançado o modelo unificador de todas as ciências e saberes, sintetizando em matrizes sistêmicas os processos sociais e mentais das sociedades.

Considerando que o ambiente não é simplesmente a ecologia, mas a complexidade do mundo (LEFF, 2001, p. 17), não existe um único método válido, mas sim métodos que devem dialogar na perspectiva de totalidade, sobretudo reconhecendo as singularidades de outros métodos, num processo que permita redefinir os objetos de cada ciência a partir da materialidade da vida (LEFF, 2003). A abordagem sistêmica preconiza a possibilidade de conflitos num sistema, mas não esmiúça essa noção, pois dela decorrem problemas pelos quais o sistema se torna harmônico, funcional, sintético, incapaz de ser pensando numa totalidade antagônica, sem a qual não há transformação. Ou seja, o conflito nessa abordagem é reduzido ao sentido de diversidade natural ou anomalia, não se constituindo a partir da desordem da vida e das estruturas históricas que formam a realidade complexa (LOUREIRO, 2006b). Quer dizer, o conflito é constatado como uma fragilidade do sistema, uma falha a ser superada quando o ser humano atingir seu estado de integração harmônica com a natureza.

Outro elemento crítico a ser elencado nesse enfoque é a possibilidade de buscar recompor e readequar as relações de maneira que estas funcionem plenamente equilibradas, sendo isso também aplicado ao modo de funcionamento do sistema social. Tal horizonte compreensivo acarreta uma visão política reformista, em que a EA se insere para cumprir a função social de adaptar as pessoas a um determinado modo de organização social, como se elas fossem a-históricas. Loureiro (2006b, p. 138) critica tal argumento, afirmando que:

Entender a relação sociedade-natureza como uma relação ideal ou genérica naturaliza o que é social, no sentido de perda de historicidade, e estabelece de modo apriorístico o que é uma interação perfeita da humanidade com a natureza. Estas concepções fragilizam a possibilidade de construção, pelos educadores ambientais, de um projeto societário alternativo e de uma prática educativa crítica, cidadã e popular. [...] Cumpre ter presente que a humanidade não se constitui como unidade homogênea $\mathrm{e}$ 
que as condições decorrentes da atuação humana no ambiente são definidas em decorrência de cada modo de vida social, em interação com as condições ecológicas de sustentação. A visão que o marco teórico emancipatório em Educação Ambiental tem da humanidade é que esta é a unidade dialética com a natureza, em que os sujeitos são pensados concretamente e não abstratamente.

Em relação com a perspectiva dialética e complexa assumida neste texto, compreendemos que não há um todo somado e descolado do movimento contínuo de desordem/interação/ordem/organização. Assim, em termos de implicação política de tal postura epistêmica, a vertente sistêmica busca minimizar os conflitos entre classes sociais em nome da cooperação, levando-os à harmonia com a natureza, como se existisse um estado absoluto e atemporal. Não leva em conta o modo como os entes são definidos em sociedade e o seu movimento para além dos imperativos éticos e das ideias (LOUREIRO, 2006b). Além disso, não apresenta como pressuposto da ação pedagógica a construção participativa de temas geradores (TOZONI-REIS, 2006), em que o saber coletivo e problematizador do real se faz presente. Assim, tal direcionamento se mostra antagonista de um dos princípios elementares de Paulo Freire (1993), que considera a problematização e a tomada de consciência coletiva do real inerentes ao processo educativo e de intervenção rumo à transformação social.

Compreendemos que o pensamento dialético, ancorado na pedagogia de Freire, enfatiza a educação como processo permanente, coletivo e cotidiano por meio do qual refletimos e agimos. Isso implica transformarmos a realidade da vida estando alicerçados no conflito e no princípio da incerteza enquanto maneiras de estabelecer movimentos emancipatórios. Situamos e entendemos desta forma os limites do enfoque sistêmico no campo ambiental:

O importante para esta vertente não é pensar processos educativos que associem a mudança pessoal à mudança societária como polos indissociáveis na requalificação de nossa inserção na natureza e na dialetização entre sujetividade-objetividade, mas sim pensar a transcendência integradora, a transformação da pessoa pela ampliação da consciência, como caminho único para se obter a união com a natureza, subordinando a racionalizada à subjetividade. (LOUREIRO, 2006b, p. 141)

No que tange à aproximação com a pesquisa em EA crítica e materialista, ter a visão sistêmica significa esvaziar de sentido a prática pedagógica, o que fragiliza as formulações teóricas ambientalistas por sinalizar uma educação (o todo) sem interlocução com suas partes (pessoas, grupos sociais, instituições e relações). Nesse sentido, não se compreende a complexidade da educação e seu movimento contraditório através da reflexão crítica dos processos emancipatórios (LOUREIRO, 2006b). Com isso, chegamos ao exame da segunda tendência: a visão materialista.

\subsection{A interdisciplinaridade e a produção histórico-social do conhecimento (visão materialista)}

A visão materialista é uma tendência que reúne esforços no sentido de apreender o desafio da interdisciplinaridade na tessitura que é estabelecida entre os processos de produção da existência e de produção do conhecimento. Para essa abordagem, a concepção de interdisciplinaridade radicaliza o conceito de história, tendo a história como critério maior e a tensão como expressão instituinte da realidade. Citamos o que Marx e Engels evidenciam como pressupostos para os homens "fazerem a história", o que inclui a produção do conhecimento:

O primeiro pressuposto de toda a existência humana e, portanto, de toda a história, é que os homens devem estar em condições de viver para poder "fazer história". Mas, para viver, é preciso antes de tudo comer, beber, ter habitação, vestir-se e algumas coisas mais. O primeiro ato histórico é, portanto, a produção dos meios que permitam a satisfação destas necessidades, a produção da própria vida material, e de fato este é um ato histórico, uma condição fundamental de toda a história, que ainda hoje, como 
há milhares de anos, deve ser cumprido todos os dias e todas as horas, simplesmente para manter os homens vivos. (MARX; ENGELS, 1987, p. 39)

A filiação a essa tendência implica deslocar a discussão que se debruça sobre o sujeito dotado de vontade, capaz de superar o suposto caos em que se encontra o mundo acadêmico, indo além da filosofia do sujeito (BIANCHETTI; JANTSCH, 2004), para então centrar o debate na relevância da história (enquanto construção humana). Vê-se que os discursos e as justificativas que envolvem a produção e veiculação do conhecimento nos diferentes momentos da história encaminharam-se para a fragmentação e para a divisão do conhecimento em ciências particulares. Em outros momentos, procurou-se praticar a interdisciplinaridade, seja através de práticas ou de vigorosos discursos absolutizadores, que privilegiaram ora um, ora outro polo (fragmentação versus integração).

Bianchetti e Jantsch (2003, p. 9) se posicionam de forma bastante crítica sobre essa questão:

pode-se também aventar a hipótese de que muitas das discussões sobre a
interdisciplinaridade, hoje, não extrapolam o campo da metafísica. Caso as discussões
sobre as possibilidades e limites da interdisciplinaridade se originassem ou estivessem
ancoradas na materialidade constitutiva do espaço-tempo dos dias de hoje ficaria
evidente que é mais fácil, na produção e veiculação do conhecimento, sair-se melhor
do espaço do interdisciplinar do que da especialidade. E esta facilidade decorre não
de uma vontade particular das pessoas, mas sim da complexidade que caracteriza os
objetos que demandam análise e compreensão e que constituem, que dão corpo, no
caso específico das escolas e universidades, àquilo que se chama de currículo. Mesmo
que alguém decidisse que iria pesquisar, construir, falar, veicular conhecimentos do
lugar da especialidade isto seria impossível uma vez que a compreensão de um
objeto/assunto/problema demandaria o aporte de mais de uma ciência ou disciplina.
A questão aqui a colocar é: qual é efetivamente a fronteira de um campo de
conhecimento, de uma disciplina? Se é que é possível delimitar as fronteiras entre os
campos de conhecimento, das disciplinas, é necessário, contudo, que se reconheça a
natureza permeável dessas fronteiras.

É a concepção complexa da relação disciplinar/interdisciplinar que compreendemos ser mais adequada no processo de produção do conhecimento, indicando uma definição que não polarize, mas, ao contrário, atue no tensionamento da relação especialização $\times$ generalidade em direção à interdisciplinaridade. Logo, assume-se que a interdisciplinaridade, enquanto princípio mediador entre as diferentes disciplinas, não poderá jamais ser elemento de redução a um denominador comum. A interdisciplinaridade é o princípio da máxima exploração das potencialidades de cada ciência, da compreensão dos seus limites, mas, acima de tudo, é o princípio da diversidade e da criatividade (ETGES, 1993).

Logo, o conceito materialista de história aponta que a realidade é dialética (caminha pela negação da negação) e que o conhecimento, na sua dialeticidade, é um construto humano passível de muitas objetivações. Partindo desse conceito, não nos posicionamos a favor de qualquer unidade metafísica ou formal da interdisciplinaridade na pesquisa em EA. Nosso entendimento da interdisciplinaridade é, portanto, dialético. Finalizando a trilha de nossa exposição, chegamos à relação entre interdisciplinaridade e complexidade para a pesquisa em EA crítica.

\section{Interdisciplinaridade, complexidade e pesquisa em EA: implicações epistêmicas}

A interdisciplinaridade, enquanto pressuposto constitutivo da identidade da EA, não é um princípio epistêmico que legitima determinados saberes e relações de hierarquia entre as ciências, nem um método único para articular conhecimentos capazes de produzir uma "metaciência". Constitui-se numa prática intersubjetiva que associa conhecimentos científicos 
e não científicos, relacionando o intuitivo, o cognitivo e o sensorial, buscando a construção de conhecimentos que se abram para novas concepções e compreensões do mundo, propondo a constituição do sujeito integral.

Apresentando-a de maneira pública, a interdisciplinaridade expõe suas dificuldades culturais e operacionais para romper com o paradigma disciplinar numa sociedade que induz à fragmentação, à individualização e à competição nas ciências. Consequência disso é a fragmentação da realidade, expressa na institucionalização das disciplinas e na forma como a ciência é produzida. Esse aspecto inclui o modo como a ciência é validada em momentos sociais particulares (relações de produção, hierarquia entre ciências, interesses sociais e econômicos), gerando recortes parciais da realidade segundo finalidades que distinguem os diversos campos de conhecimento.

Também é necessário esclarecer que a história da formação das disciplinas científicas não é semelhante à história de criação de disciplinas escolares, ou seja, que o conhecimento científico não se desdobra sobre o conhecimento escolar em termos de estruturação (LOUREIRO, 2006e). O modelo ocidental dominante se definiu no marco de expansão do capitalismo e de seu ideário cartesiano ou naturalista-idealista. Nestes, a dicotomia naturezacultura permanece, pois não consegue conviver com a tensão da diversidade (LOUREIRO, 2006a). Segundo Loureiro (2006e, p. 128):

Quando se associa a disciplinaridade como característica à modernidade, recaímos noutro generalismo, posto que este momento civilizatório não é uma unidade no modo de pensar e agir no mundo. Há traços gerais que dão certo sentido de unidade a uma determinada concepção de civilização que a caracteriza, mas que se traduzem em tendências distintas e antagônicas, a partir das quais se fez a própria crítica à noção de civilização moderna e à disciplinarização da ciência e da educação. Tais tendências e tradições filosóficas dão margem, inclusive, a conotações pós-modernas que vão desde as afinadas com o neoliberalismo e o atomismo até concepções coletivistas e emancipatórias.

Em relação ao debate epistêmico-político sobre a interdisciplinaridade, apontamos duas perspectivas distintas que representam compreensões e projetos opostos no desenvolvimento dessas práticas. A primeira é adepta da teoria crítica, do conceito de totalidade e de complexidade, e a segunda decorre de um monismo epistêmico e do positivismo (LOUREIRO, 2006a). Por opção epistemológica e política, entendemos que a primeira perspectiva indicada é a mais adequada para a formulação de EA que almejamos. Tomando-a como base, não podemos mais aceitar qualquer tipo de reducionismo na EA, pois, segundo Layrargues (2006, p. 12):

Pensar de forma complexa implica fazer com que o agir seja consciente, no sentido de se saber qual o terreno em que nos movemos, o alcance de determinada ação, apresentando coerência entre o que se quer, a base teórica da qual se parte, onde se quer chegar e quem se beneficia com o processo. Qual enquadramento, pano de fundo ou leitura da realidade há.

Assim, distantes de esgotar o diálogo entre a abordagem dialética e a da teoria da complexidade, que é vasto e já foi realizado com maestria e profundidade (LOUREIRO, 2006a, LOUREIRO; VIÉGAS, 2007, 2012; VIÉGAS, 2010), abordaremos alguns elementos que nos parecem relevantes para a formulação teórica da interdisciplinaridade à luz da complexidade de Edgar Morin. Entendemos que o esforço de diálogo entre a interdisciplinaridade, o materialismo histórico-dialético e o paradigma da complexidade pode ser visto

a partir de uma necessidade criada no exercício teórico-prático da educação ambiental: a busca de uma compreensão complexa da realidade em seu movimento dinâmico e contraditório. Essa busca nos aproximou da teoria-método da complexidade de Edgar Morin, mas tendo como orientação, principalmente do ponto de vista ontológico e político-epistemológico, o materialismo histórico-dialético de Karl Marx. (LOUREIRO; VIÉGAS, 2012, p. 14) 
Um dos problemas mais comuns vistos na interdisciplinaridade decorre do processo de banalização da teoria e da dinâmica conflitiva e dialética que não é explicitada entre as variadas tendências do campo ambiental (COSTA E LOUREIRO, 2012; COSTA E LOUREIRO, 2013c; LOUREIRO, 2006a, LOUREIRO, 2007b; LOUREIRO, 2014). Tal fator muitas vezes leva a falsos consensos, que servem de parâmetro para ações desconexas da realidade que, com isso, são validadas em determinados momentos pela dinâmica interna do campo (LOUREIRO, 2006a). Em termos de implicações políticas, adotar a perspectiva dialética na interdisciplinaridade significa reconhecer o sentido real da EA no processo educativo, buscando a capacidade de transformação social à qual é vinculada o modo de (re)produção da vida humana.

Portanto, recordamos que a dialética (LOUREIRO; VIÉGAS, 2007, p. 14) afirma princípios que trazem em seu horizonte implicações para a interdisciplinaridade: contradição e unidade de contraditórios (antagonismo, interpolação e complementariedade de opostos), superação (negação, incorporação e inovação, continuidade e criação na complexificação da materialidade da vida) (MÉSZÁROS, 2006), totalidade (princípio da inter-relação formando conjuntos auto-organizados e estruturados), transformação (princípio do movimento universal), historicidade, entre outros (BORNHEIM, 1977).

Consequentemente, a interdisciplinaridade pressupõe conceitos comuns à dialética marxista e à abordagem complexa, dos quais podemos frisar dois elementos comuns para tais relações (LOUREIRO; VIÉGAS, 2007, p. 16-18):

1) partem do pressuposto de que a realidade envolve movimento ou é o próprio movimento, saindo dos padrões idealistas de filosofia e atemporais de ciência. Como diria Engels "vida é movimento. O estático é a não vida" [...], retomando uma máxima de Heráclito: o sentido do universo é a mudança. Na abordagem sistêmica, os denominados hólons (partes que são em si totalidades) emergem a partir das interações espontâneas de outros hólons. Na abordagem dialética, a síntese emerge da oposição, interpolação e complementaridade entre tese e antítese, que se combinam em pares múltiplos, simultâneos e não lineares na causalidade, em que cada polo é uma totalidade inserida em outras totalidades. Portanto, em ambas não há um todo e suas partes, mas "todos-partes" em movimento. [...]

3) Na dialética, cada estágio da sociedade atinge suas limitações, as quais podem iniciar o processo de autossuperação. As limitações criam "contradições insolúveis" ou antagonismos estruturais que podem caminhar para a superação, passando para um grau mais complexo de organização. Essa nova ordem, contudo, igualmente possui suas contradições, que geram perturbações e possibilidades de superação e assim sucessivamente [...]. A abordagem sistêmica se caracteriza pelo reconhecimento de que estruturas ou sistemas são uma característica do universo. Uma vez constituído, o hólon procura manter sua identidade por meio: da preservação de suas partes e suas relações (organização); das relações com outros hólons do mesmo nível, dando origem a novos hólons em um nível superior (emergência do complexo); da tendência em adaptar-se às relações (adaptação ao ambiente); e da decomposição quando fracassa na preservação de suas partes.

Também consideramos que existe um ponto distintivo entre as relações, no segundo item mencionado, que impede simples justaposições entre as abordagens sistêmicas e a dialética marxista. Na dialética existe a compreensão de que os processos sócio-históricos se vinculam ao todo (natureza), definindo-o em suas particularidades, a qual é conhecida como relação universal-singular-particular. Assim, as relações sociais não se associam às relações ecológicas por aproximação, como ocorre em análises próprias da teoria de sistemas. Como seria pensar de modo complexo a interdisciplinaridade? Para Loureiro e Viégas (2007, p. 11):

As denominadas ciências da complexidade começam a se constituir em meados do século XX, alcançando importantes repercussões teóricas e afetando diferentes visões de mundo nas décadas subsequentes. Contudo, devemos destacar que estas não se consolidam em um momento histórico-social qualquer. Surgem no contexto de 
expansão da terceira fase do capitalismo, que rompe com o período da "Grande Indústria" e passa a se reproduzir com forte ênfase nos processos especulativos financeiros e na utilização das ciências, do conhecimento, da tecnologia e da informação como poderosas forças produtivas, lideradas pelo complexo empresarialmilitar, destacadamente o dos Estados Unidos. Assim, o capital, saindo de sua fase de expropriação material mais direta, de equivalência forma-conteúdo, potencializa e diversifica processos de acumulação e dominação, ao vincular à necessidade de especialidade técnica decorrentes da divisão do trabalho (a famosa fragmentação do saber) os conhecimentos multidimensionais e o uso da informação em tempo real. Vivemos, portanto, em um momento regido não mais exclusivamente por um princípio mecânico-industrial de organização da produção, mas também por um princípio cibernético, flexível, com profundos efeitos na subjetividade humana.

Com essa compreensão histórica em vista, consideramos a relevância desta discussão para a construção epistemológica da interdisciplinaridade na EA pondo em aproximação a tradição marxista e a teoria da complexidade formulada por Edgar Morin. Este autor afirma a validade da dialética elaborada por Marx, pois Morin faz parte de um conjunto de autores reconhecidos no campo ambiental cujos conceitos são tomados indistintamente por aqueles que pretendem negar a tradição crítica e pelos que se utilizam de premissas da pedagogia conservadora na EA.

Sendo assim, consideramos que nada é mais dialético, dialógico e crítico do que a constante capacidade de reflexão de teorias que levem em conta os contextos históricos em que estamos inseridos e as necessidades de transformação. $\mathrm{O}$ evidente é dizer que a teoria da complexidade de Morin envolve fatores da dialética e da visão sistêmica, indo além de ambas na formulação de algo próprio, mas com capacidade de crítica e análise de suas implicações e equívocos, como qualquer outra construção metodológica (LOUREIRO, 2006a). Levando em conta os argumentos acima, Loureiro (2006a, p. 111) afirma:

A concepção dialética implica compreender o desenvolvimento histórico sendo efetuado por contradições e movimentos de superação destas contradições. Aí não há apenas relações recíprocas entre fenômenos e esferas sociais, mas uma totalidade de elementos em movimento, fluxo e transformação [...]. A demonstração das contradições internas ao capitalismo, seus antagonismos, e de suas implicações sobre a coisificação da vida e alienação humana evidencia a possibilidade histórica de superação desse sistema [...]. A explicitação da relação dialética entre os fenômenos políticos, religiosos, ideológicos e os conflitos de classe permite o entendimento do modo de organização social e dos processos aí engendrados na produção do ser humano [...]. A compreensão das implicações decorrentes da relação entre história humana e natureza modificada possibilita compreendermos a especificidade da natureza humana. [...] O princípio de que o ser humano é social por natureza, logo, isso implica compreender que a realização de sua natureza se dá em sociedade.

Feita essa argumentação, frisamos que foi a partir de Hegel que o contraditório passou a ser norma do pensamento, sendo um princípio que gera o movimento entre conservação e superação, e permitindo o entendimento complexo da totalidade e da organização da vida. Para o filósofo, são a estrutura de pensamento e o método que permitem apreendermos a realidade como contraditória e em constante transformação. No que tange à reflexão sobre o papel da ciência, ousamos assinalar que o embate interdisciplinar passa também a ter na contradição seu fundamento para interpretar a realidade visando transformá-la!

Em Marx, o antagonismo decorre de situações próprias à sociedade de classes, no sentido dialético, pois o enfrentamento político na explicitação dos conflitos passa pela superação de uma determinada situação e pelo surgimento de outra condição (LOUREIRO, 2006a). Já a contradição como princípio tem seu complementar em relação a um movimento de superação pela negação, de transformação permanente, formando o todo. $\mathrm{Ou}$ seja, o 
antagonismo desaparecerá mediante a superação do capitalismo, mas a contradição permanecerá, uma vez que é inerente à história e ao movimento da natureza.

Adentrando o debate acerca da relação sociedade-natureza, sintetizamos alguns princípios da dialética que podem ser incorporados ao pressuposto interdisciplinar a partir dos escritos de Harvey (1996 apud LOUREIRO, 2006b, p. 145-146):

1. Elementos são demarcados por todos estruturados. A coisa ou o sistema devem ser entendidos e fundamentados nas relações que os constituem. Nada se define em si como parte isolada. Tudo é fluxo e processo relacional, singularidade e totalidade.

2. Elemento e sistema são perpetuamente constituídos e reconstituídos por múltiplos processos.

3. Partes e todos são mutuamente constitutivos de cada um, o que implica dizer muito mais do que a existência de retroalimentação entre estes.

4. Há intercâmbio entre sujeito e objeto, causa e efeito, em consequência os organismos são sujeitos e objetos da evolução e os indivíduos humanos, sujeitos e objetos do processo de mudança social.

5. Mudança é a norma das coisas e dos sistemas e a História é feita pelo movimento permanente de transformação social, cultural, política e econômica, com profundas implicações sobre o ambiente, o sentido de natureza e de realização da natureza humana.

Assim, podemos estabelecer uma relação com os principais elementos do chamado paradigma da complexidade elencados por Morin para a interdisciplinaridade, dentre os quais podemos destacar (LOUREIRO, 2006a, p. 121):

Os fenômenos complexos são passíveis de desordem e ordem em interação contínua. [...] Nenhum corpo pode ser concebido fora de interações que o constituíram e das quais participa. Propriedades novas emergem da interação entre as partes e destas com o todo, e entre diferentes níveis de realidade. [...] Os fenômenos complexos são marcados pela interação sujeito-objeto. O conhecimento do complexo implica desconhecimento parcial da realidade.

O paradigma da complexidade exige comunicação entre as ciências, promovendo uma reflexão filosófica e científica. Morin e Kern (1995) define que o paradigma da complexidade deve compreender o princípio de inteligibilidade, abordando o físico, o biológico e o antropossocial. A complexidade deve vir aliada à compreensão de que o conhecimento científico possui os seguintes aspectos:

\begin{abstract}
ao progredir por eliminação dos erros, o conhecimento científico não garante o aumento de verdades; nem o conhecimento científico, nem o espírito humano conseguem esgotar o sentido completo do real; eliminar a ignorância não é sinônimo de progresso científico; os progressos do conhecimento devem unir-se ao progresso da ignorância; são as regras do jogo entre a verdade e o erro que definem o que é a verdade científica, uma vez que esta não está contida nas suas teorias. (FLORIANI; KNECHTEL, 2003, p. 25)
\end{abstract}

Para a compreensão marxista (KOFLER, 2010), existe uma relação dialética entre a sociedade e o conhecimento. Por um lado, o conhecimento aparece como uma construção social; por outro, a produção de novos conhecimentos contribui para transformação social. Categoria central para compreender a dialética é o conceito de totalidade, segundo o qual o todo contém as partes que o constituem. Isso significa que as coisas estão em constante relação recíproca, e nenhum fenômeno da natureza ou do pensamento pode ser compreendido isoladamente, fora dos fenômenos que o rodeiam. Em outras palavras, numa totalidade o conhecimento das partes e do todo pressupõe uma reciprocidade, que confere significado tanto ao todo quanto às diversas partes que o formam. São determinações que perpassam e completam a transversalidade do todo, de modo que não pode haver conhecimento de um todo ou de partes. Se amputada a totalidade, isolamos seus elementos entre si e em relação à totalidade. No entendimento de Loureiro e Viégas (2012, p. 18): 
A totalidade a partir da dialética marxiana não pode ser confundida com a concepção de conjunto completo dos elementos que constituem uma realidade (associado a um todo absoluto, lógico e/ou estático), mas remete a um conjunto estruturado de relações mutuamente determinadas e mediadas, que formam uma unidade que me permite compreender algo. Como a realidade é movimento na/da história, reconstruída pela ação prática e transformadora dos seres humanos (em suas múltiplas mediações que nos constituem como indivíduos: família, grupos sociais com os quais nos relacionamos e criamos identidades, tempo histórico, classe social etc.), a ideia de totalidade também transborda para "a forma de ver/enxergar" esta realidade, ou seja, transborda para a subjetividade e para um método (no sentido de modo pelo qual concebemos a realidade).

De outro lado, o paradigma complexo busca diferenciar teorias que se referem aos diversos tipos de fenômenos, fundando uma ideia de sistema em um complexo de unidade no múltiplo, assim como busca constatar que a organização não supõe apenas a ordem, mas também a desordem. Para esse paradigma, é necessário uma reforma no pensamento que incorpore e reconheça as incertezas e contradições. De acordo com Morin e Kern (1995, p. 161), abstração e contextualização são dois mecanismos do conhecimento atual, ou seja, uma coisa é ter acesso às informações, e outra é saber articulá-las. Para conhecer e reconhecer os problemas do mundo, exige-se uma reforma no pensamento que necessita da contextualização do conhecimento. Por conseguinte, a relação do homem com a natureza não pode ser fragmentada, pois o ser humano é natural-sobrenatural. Quer dizer, pensamento, consciência e cultura se diferenciam e se confundem ao mesmo tempo com a natureza física.

Assim, argumentamos que no desenvolvimento interdisciplinar é preciso considerar os componentes ontológicos e históricos de intervenção humana no ambiente. Isso sugere aos processos de EA crítica uma reflexão sobre a dinâmica da relação sociedade-natureza, pois, sem essa dimensão, o debate ambiental se torna simplificado, fragmentado e despolitizado pela negação da materialidade e das contradições contidas nas relações sociais.

\section{Considerações finais}

A problematização da interdisciplinaridade nos termos definidos neste ensaio permite inserir a categoria, do ponto de vista epistêmico e político, no questionamento das relações sociais estabelecidas sob o marco capitalista, sendo premente que as pesquisas em EA crítica ultrapassem os discursos aparentemente neutros pontuados pelos documentos ambientais "oficiais". Tal aspecto se verifica quando, na EA, a interdisciplinaridade é debatida academicamente de forma ideal ou formal, sem entrar na aridez e na materialidade política do conceito.

Levamos em conta que a interdisciplinaridade na produção do conhecimento é fundada no caráter dialético da realidade social, que é una e diversa, e na natureza intersubjetiva de sua apreensão (FRIGOTTO, 2004). Ao relacionar interdisciplinaridade e práxis pedagógica emancipatória estamos nos referindo de forma mais direta aos processos complexos e à historicidade do real. Isso nos remete a um cenário marcado por diferenças epistêmicas, no qual a complexidade no campo de investigação da EA ganha visibilidade e estranhamento, sem haver uma preocupação de revelar diferenças e contradições marcantes de ordem conceitual, histórica, metodológica e epistêmica.

Se, para Marx, o concreto é concreto porque é a unidade do diverso, síntese de múltiplas determinações (MARX, 1982), os sujeitos e os fatos concretos, à medida que conhecemos a totalidade que é definida, se inserem num exercício complexo de totalização. Pois tudo se liga a tudo, de modo que nossas ações necessitam de uma visão contextualizada para que tenhamos clareza daquilo que é feito, ao contrário de visões fragmentadas e lineares, que nos induzem a compreensões parciais e à "falsa consciência" do real (LOUREIRO, 2006a). 
Admitimos a conveniência de um diálogo aberto e crítico entre a EA e a teoria da complexidade, pois consideramos que a mobilização de um pensamento complexo poderá ampliar as condições reflexivas e propositivas em vista de ações educativas transformadoras. Ficando clara a nossa opção pelo materialismo histórico-dialético de Marx, reconhecemos a importância, o mérito e a atualidade da teoria da complexidade de Morin em relação às contribuições que esta pode trazer para a pesquisa em EA, mais propriamente em sua questão interdisciplinar. Torna-se evidente que a construção moriniana não pode ser descolada de um movimento histórico, assim como da interdisciplinaridade, em busca de uma concepção de mundo menos linear e mais crítico, observando as múltiplas determinações que constituem a realidade. Asseveramos que:

não devemos julgar que as ideias de totalidade e de práxis histórica se desfazem diante de uma teoria sistêmica de compreensão do real. Compreender como a complexidade moriniana avança sobre o conceito de totalidade, agregando novos elementos das ciências do século XX, pode contribuir na retomada do vigor da filosofia da práxis, trazendo um estímulo a novas reflexões para o campo da educação ambiental. (LOUREIRO; VIÉGAS, 2012, p. 23)

Diante de tal perspectiva complexa, apontamos que a opção epistemológica e metodológica materialista torna-se compatível com o paradigma complexo, dialético, histórico, transformador e libertário, de forma que a interdisciplinaridade é incorporada à visão emancipatória na EA. Portanto, teoria da complexidade, interdisciplinaridade e dialética marxista se aproximam e contribuem para os projetos de transformação societária, quer redefinindo paradigmas e modos de pensar e atuar, individual ou coletivamente, ou trazendo concretude à superação do projeto capitalista (LOUREIRO, 2006a).

\section{Referências}

BERTALANFFY, L. V. Teoria geral dos sistemas. Petrópolis: Vozes, 1977.

BIANCHETTI, L.; JANTSCH, A. Interdisciplinaridade e práxis pedagógica emancipadora. In: SEMINÁRIO INTERNACIONAL EDUCAÇÃO INTERCULTURAL, GÊNERO E MOVIMENTOS SOCIAIS: IDENTIDADE, DIFERENÇA E MEDIAÇÕES, 2., 2003, Florianópolis. Anais [...]. Florianópolis: Editora da UFSC, 2003. p. 1-12. Disponível em: https://bit.ly/2nYy0D3. Acesso em: 18 out. 2019.

BIANCHETTI, L.; JANTSCH, A. (org.). Interdisciplinaridade: para além da filosofia do sujeito. In: BIANCHETTI, L.; JANTSCH, A. Interdisciplinaridade: para além da filosofia do sujeito. Petrópolis: Vozes, 2004. p. 11-24.

BORNHEIM, G. A dialética: teoria, práxis: ensaio para uma crítica da fundamentação ontológica da dialética. São Paulo: Edusp, 1977.

COSTA, C. A. Marketing ecológico: uma reflexão sobre as relações perversas do "ambientalismo verde" na sociedade capitalista. Derecho y Cambio Social, Lima, ano 9, n. 29, p. 1-10, 2012a. Disponível em: https://bit.ly/31otag5. Acesso em: 18 out. 2019.

COSTA, C. A. Dialética marxista e interdisciplinaridade: contribuições ao debate ambiental crítico. Delos: Desarrollo Local Sostenible, Málaga, v. 5, n. 13, p. 1-8, 2012b. Disponível em: https://bit.ly/2MOAhZS. Acesso em: $1^{\circ}$ maio 2012.

COSTA, C. A. Educação ambiental crítica e interdisciplinaridade: premissas para o debate. Derecho y Cambio Social, Lima, ano 10, n. 34, p. 1-10, 2013. Disponível em: https://bit.ly/35Q6Jnw. Acesso em: 18 out. 2019. 
COSTA, C. A.; LOUREIRO, C. F. Interdisciplinaridade, dialética e ambiente: aproximações epistêmicas. In: SEMINÁRIO INTERNACIONAL DE EDUCAÇÃO EM CIÊNCIAS, 1., 2011, Rio Grande. Anais [...]. Rio Grande: FURG, 2011. v. 2, p. 99-102.

COSTA, C. A.; LOUREIRO, C. F. Implicações do método dialético no discurso interdisciplinar: aproximações à luz da práxis ambiental. In: ANPED SUL, 9., 2012, Caxias do Sul. Anais [...]. Caxias do Sul: UCS, 2012. p. 1-17. Disponível em: https://bit.ly/2OVGgyK. Acesso em: 18 out. 2019.

COSTA, C. A.; LOUREIRO, C. F. Educação ambiental crítica: contribuições à luz de Enrique Dussel e Paulo Freire. In: ENCONTRO DE PESQUISA EM EDUCAÇÃO AMBIENTAL, 7., 2013, Rio Claro. Anais [...]. Rio Claro: Unesp, 2013. p. 1-14. Disponível em: https://bit.ly/35JWYHe. Acesso em: 18 out. 2019.

ETGES, N. Produção do conhecimento e interdisciplinaridade. Educação e Realidade, Porto Alegre, v. 18, n. 2, p. 73-82, 1993.

FLORIANI, D.; KNECHTEL, M. Educação ambiental, epistemologias e metodologias. Curitiba: Vicentina, 2003.

FOLLARI, R. Interdisciplina e dialética: sobre um mal entendido. In: JANTSHI; Ari; BIANCHETTI, L. (Orgs.). Interdisciplinaridade: para além da filosofia do sujeito. Petrópolis: Vozes, 2004. p. 127-141.

FREIRE, P. Pedagogia do oprimido. 22. ed. São Paulo: Paz e Terra, 1993.

FRIGOTTO, G. A interdisciplinaridade como necessidade e como problema nas ciências sociais. In: JANTSHI; A; BIANCHETTI, L. (Orgs.). Interdisciplinaridade: para além da filosofia do sujeito. Petrópolis: Vozes, 2004. p. 25-49.

GONÇALVES, C. W. P. Possibilidades e limites da ciência e da técnica diante da questão ambiental. Geosul, Florianópolis, v. 3, n. 5, p. 7-40, 1988. Disponível em: https://bit.ly/2J9VnAG. Acesso em: 21 out. 2019.

KOFLER, L. História e dialética. Rio de Janeiro: Editora UFRJ. 2010.

LAYRARGUES, P. Para que a educação ambiental encontre a educação. In: LOUREIRO, C. F. B. Trajetória e fundamentos da educação ambiental. São Paulo: Cortez, 2006. p. 11-18.

LOUREIRO, C. F. B. Educação ambiental transformadora. In: LAYRARGUES, P. (coord.). Identidades da educação ambiental brasileira. Brasília, DF: Ministério do Meio Ambiente, 2004. p. 65-82. Disponível em: https://bit.ly/33JT3IQ. Acesso em: 18 out. 2019.

LOUREIRO, C.F.B. Trajetória e fundamentos da Educação Ambiental. São Paulo: Cortez, 2006 a.

Complexidade e dialética: contribuições à práxis política e emancipatória em educação ambiental. Educação e Sociedade, Campinas, v. 27, n. 94, p. 131-152, 2006b. Disponível em: https://bit.ly/2MvSWed. Acesso em: 18 out. 2019.

. Problematizando conceitos: contribuição à práxis da educação ambiental. In: LOUREIRO, C. F.; LAYRARGUES, P. P.; CASTRO, R. S. (org.). Pensamento complexo, dialética e educação ambiental. São Paulo: Cortez, 2006e. p. 104-161. 
. A pesquisa-ação participante e educação ambiental: uma abordagem dialética e emancipatória. In: TOZONI-REIS, M. (org.). A pesquisa-ação participativa em educação ambiental: reflexões teóricas. São Paulo: Annablume, 2007a. p. 13-56.

Pensamento crítico, tradição marxista e a questão ambiental: ampliando os debates. In: LOUREIRO, C. F. (org.). A questão ambiental no pensamento crítico: natureza, trabalho e educação. Rio de Janeiro: Quartet, 2007b. p. 13-67.

. Materialismo histórico-dialético e a pesquisa em educação ambiental. Pesquisa em Educação Ambiental, Rio Claro, v. 9, n. 1, p. 53-68, 2014.

LOUREIRO, C. F.; VIÉGAS, A. Complexidade e dialética: por uma busca de novos elementos na tradição da crítica ambiental diante dos desafios da educação ambiental. Ambiente e Educação, Rio Grande, v. 12, n. 1, p. 11-37, 2007. Disponível em: https://bit.ly/2pC1qXP. Acesso em: 18 out. 2019.

LOUREIRO, C. F.; VIÉGAS, A. Algumas considerações sobre a influência do marxismo na teoria da complexidade de Edgar Morin: aportes para a pesquisa em educação ambiental. Ambiente e Educação, Rio Grande, v. 17, n. 2, p. 13-24, 2012. Disponível em: https://bit.ly/2MtMDaQ. Acesso em: 18 out. 2019.

LOUREIRO, C. F.; VIÉGAS, A. Princípios normativos da educação ambiental no Brasil: abordando os conceitos de totalidade e práxis. Pesquisa em Educação Ambiental, Rio Claro, v. 8, n. 1, p. 11-23, 2013.

LEFF, E. Epistemologia ambiental. São Paulo: Cortez, 2001.

LEFF, E. (coord.). A complexidade ambiental. São Paulo: Cortez, 2003.

MARX, K. Para a crítica da economia política: Salário, preço e lucro: O rendimento e suas fontes; a economia vulgar. In: Os economistas. São Paulo: Abril Cultural, 1982.

MARX, K.; ENGELS, F. A ideologia alemã. São Paulo: Hucitec, 1987.

MÉSZÁROS, I. A teoria da alienação em Marx. São Paulo: Boitempo, 2006.

MORIN, E. O Paradigma perdido: a natureza humana. Lisboa: Europa-América, 1999.

O método I: a natureza da natureza. 2. ed. Porto Alegre: Sulina, 2003.

. A inteligência da complexidade. São Paulo: Fundação Peirópolis, 2000.

MORIN, E.; KERN, A. Terra pátria. Porto Alegre: Sulina, 1995.

QUINTAS, J. S. Educação no processo de gestão ambiental pública: a construção do ato pedagógico. In: LOUREIRO, C. F. B; LAYRARGUES, P (org.). Repensar a educação ambiental: um olhar crítico. São Paulo: Cortez, 2009. p. 33-77.

. A Relevância Social e a Consistência Epistêmica da Pesquisa em Educação. Revista Educação: teoria e prática, vol. 9, n 16, jan-jun. 2001 e nº 17, jul-dez, 2001, p. 10-16.

TOZONI-REIS, M. Temas ambientais como "temas geradores": contribuições para uma metodologia educativa ambiental crítica, transformadora e emancipatória. Educar em Revista, Curitiba, v. 22, n. 27, p. 93-110, 2006.

VIÉGAS, Aline. Educação ambiental e complexidade: uma análise a partir do contexto escolar. 2010. Tese (Doutorado em Ecologia Social) - Universidade Federal do Rio de Janeiro, Rio de Janeiro, 2010. 